Abstracted/indexed in Academic Search Complete, Asia Journals Online, Bangladesh Journals Online, Biological Abstracts, BIOSIS Previews, CAB Abstracts, Current Abstracts, EMBASE/Excerpta Medica, Google Scholar, HINARI (WHO), International Pharmaceutical Abstracts, Open J-gate, Science Citation Index Expanded, SCOPUS and Social Sciences Citation Index;

ISSN: $1991-0088$

\title{
Imidazole and its derivatives as potential candidates for drug development
}

\author{
Amara Mumtaz', Aamer Saeed², Nighat Fatima3, Muhammad Dawood3, \\ Hummera Rafique4 and Jamshed Iqbal3,5
}

${ }^{1}$ Department of Chemistry, COMSATS Institute of Information Technology Abbottabad, Abbottabad 22-060, Pakistan;

${ }^{2}$ Department of Chemistry, Quaid-I-Azam University, Islamabad, Pakistan; ${ }^{3}$ Department of Pharmacy, COMSATS Institute of Information Technology Abbottabad, Abbottabad 22-060, Pakistan; ${ }^{4}$ Department of Chemistry, University of Gujrat, Gujrat, Pakistan; ${ }^{5}$ Centre for Drug Development, COMSATS Institute of Information Technology Abbottabad, Abbottabad 22-060, Pakistan.

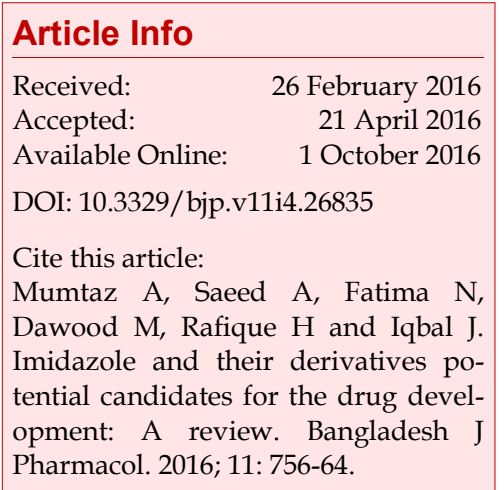

\begin{abstract}
Imidazole and its derivatives are the pharmacological significant scaffolds with the broad spectrum of activities can be synthesized in the laboratory in the single step by the action of the catalyst. The current review summarizes the role of the imidazole and its derivatives during the last decade (2005-2014) for the treatment of many diseases. Review highlights their significant contribution towards the drug development for the treatment of some fatal diseases like HIV, cancer, tuberculosis and hepatitis C. As imidazole and its derivatives continue to play an important role for the treatment of many diseases so there is a need to trigger research in this field.
\end{abstract}

\section{Introduction}

Synthetic organic chemistry is playing a significant role in the development of new drugs. In this regard, nitrogenous heterocycles have a long history in the biomedical research and always remained on the front line (Anderson and Long, 2010). Imidazole a fivemember nitrogenous heterocycle constitutes the part of many essential amino acids histidine, bovine and vitamin B12 (Bellina et al., 2007; Anderson and Long, 2010; Uçucu et al., 2001). Imidazoles (1) and their derivatives (2-3) have attracted the attention of scientists due to their significant importance for designing the targeted molecules of medicinal importance (Nagarajan et al., 2014b; Chen et al., 2014; Nagarajan et al., 2014a) which relates to the presence of polar imidazole ring, with two nitrogen atoms separated with a methylene, hydrogen bonds in which one amino hydrogen behaves as the donor while the other amino nitrogen as the acceptor (Anderson and Long, 2010). Due to the unusual ring structure many pharmaceutical

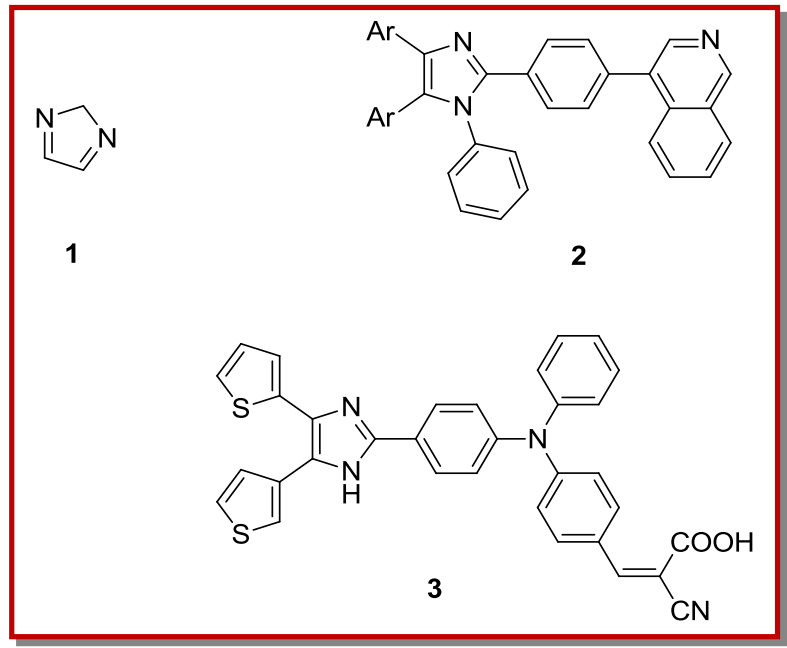

activities are associated with imidazole and its derivatives, antifungal, antibacterial (Nagarajan et al., 2013), antitumor (Chen et al., 2013b), antiviral (Sharma et al., 
2009), anti-oxidant (Sorrenti et al., 2006) and antidepressant (Dostert et al., 1990) are the known examples.

Synthesis of imidazole ring and its derivatives is carried out by using one-step condensation of diketone with aldehyde, ammonium acetate and primary aromatic amine in the presence of nanocrystalline magnesium aluminate (Safari et al., 2013), supported ionic liquidlike phase (Saffari Jourshari et al., 2013), SiO2-Pr-SO3H (Ziarani et al., 2013), clay supported titanium catalyst (Kannan and Sreekumar, 2013), brønsted acidic ionic liquid,(4-sulfobutyl)tris(4-sulfophenyl)phosphonium hydrogen sulfate (Banothu et al., 2013), nano-TiCl4.SiO2 (Mirjalili et al., 2012) I2/Cs2CO3 (Xue et al., 2014) and sulfonic acid functionalized SBA-15 nanoporous material (SBA-Pr-SO3H) catalyst (Ziarani et al., 2013).

As imidazole and its derivatives are associated with a number of biological significances so the current review will emphasized on the role of imidazole and its derivative as potential candidate for the development of drugs to treat some fatal diseases including HIV-AIDS (de Walque, 2014), cancer (Fraser et al., 2014), hepatitisC (Linas et al., 2014) and tuberculosis (Zoraghi and Reiner, 2013), etc.

\section{Pharmacological Significances}

From the literature, it is found that imidazole and their derivatives they possess potent activities against fetal diseases and playing a significant role in a fight against them.

\section{Anti-HIV activity}

Acquired immunodeficiency syndrome (AIDS) is a viral disease caused due to the special virus Human Immunodeficiency Virus type 1 (HIV-1) (Basu et al., 2009). The HIV-1 type virus destroys the lymphocytes the 'helper cell' which fight against the infections (Roy and Leonard, 2005). According to World Health Organization report, three million people were suffering from AIDS and more than five million people acquire the AIDS in the single year (AIDS, 2003). As the HIV-AIDS is increasing globally and there is a need to introduce some new drugs to help in a fight against this fatal disease. In this regard imidazole and their derivatives are playing a significant role in the treatment of disease. During the course of drugs for the treatment of HIV-AIDS, the activity is mainly focused on the interaction of the compound with the active site of the viral enzyme to inhibit its growth (Serrao et al., 2013). Derivatives of 2-(1-aryl-1H-imidazol-2-ylthio)acetamide [imidazole thioacetanilide (ITA)] was evaluated against Human Immunodeficiency Virus type-1 (HIV-1). The most significant activity was observed by compound 4 $\left(\mathrm{EC}_{50}=0.18 \mathrm{LM}\right)$ with electron withdrawing nitro group, and compound $5\left(\mathrm{EC}_{50}=0.20 \mathrm{LM}\right)$ with electron donating group at meta positions of the compounds. These two compounds were found more active as compared to the reference drugs nevirapine and delavirdine (Zhan et al., 2009).

Some 5-carbonyl-1H-imidazole-4-carboxamides were developed which were the potent inhibitor for HIV-1 integrase-LEDGF/p75 (Serrao et al., 2013) because of the presence of the imidazole moiety. Some butterflylike inhibitors of N-benzyl-imidazole derivatives were synthesized and subjected to HIV-1 inhibition activities and were found potent inhibitor due to the specific shape (Ziółkowska et al., 2010). Another target for the development of the anti HIV-1 drug is the attack of the drug on the capsid protein of the HIV virus which plays an important role in the early and later stage of the HIV -I virus life cycle. With the advancement of the organic synthesis modification on the C2, C16 and N1 of the benzimidazole group more efficient compounds with potent anti-HIV activities were formed. In this regard, series of 5-(5-furan-2-ylpyrazol-1-yl)-1H-benzimidazole (7) were synthesized and showed excellent inhibition against the assembly of HIV capsid. Modifications of the compounds at $\mathrm{C} 2, \mathrm{C} 16$, and N1 position enhanced the antiviral activities and compounds (8-10) after modification showed maximum inhibition at EC50 values (Tremblay et al., 2012).

Caparavarin (6) is a non-nucleoside drug having imidazole moiety and is under the process of drug development for the treatment of AIDS but its use is being restricted due to some side effect like inflammation etc. Loksha et al synthesized the analogs of capravarin and tested them against different wild types of HIV viruses. It was found that the compounds

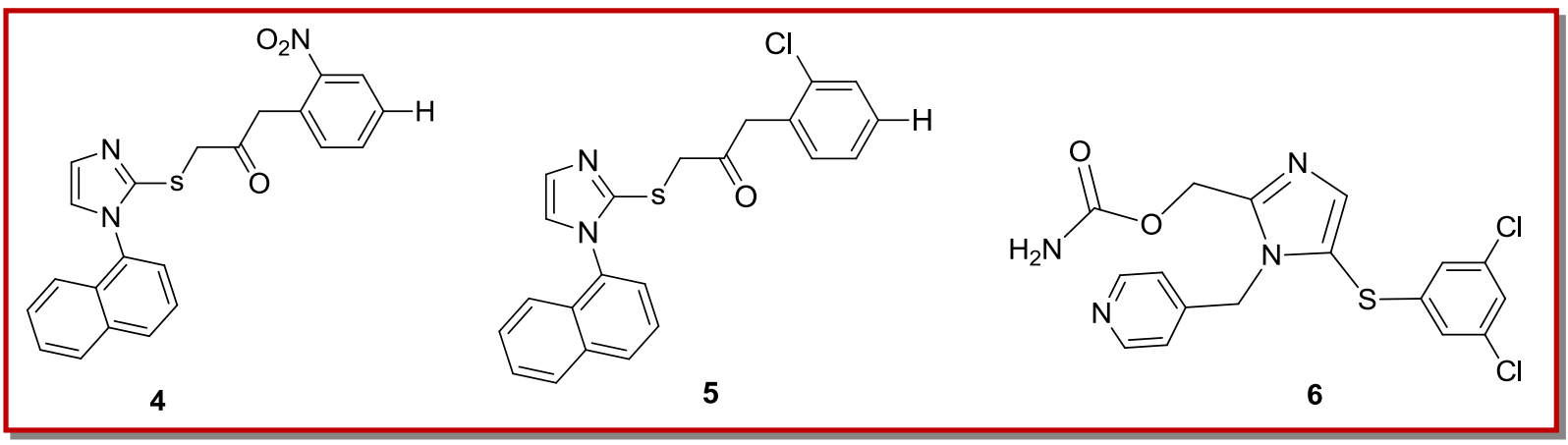




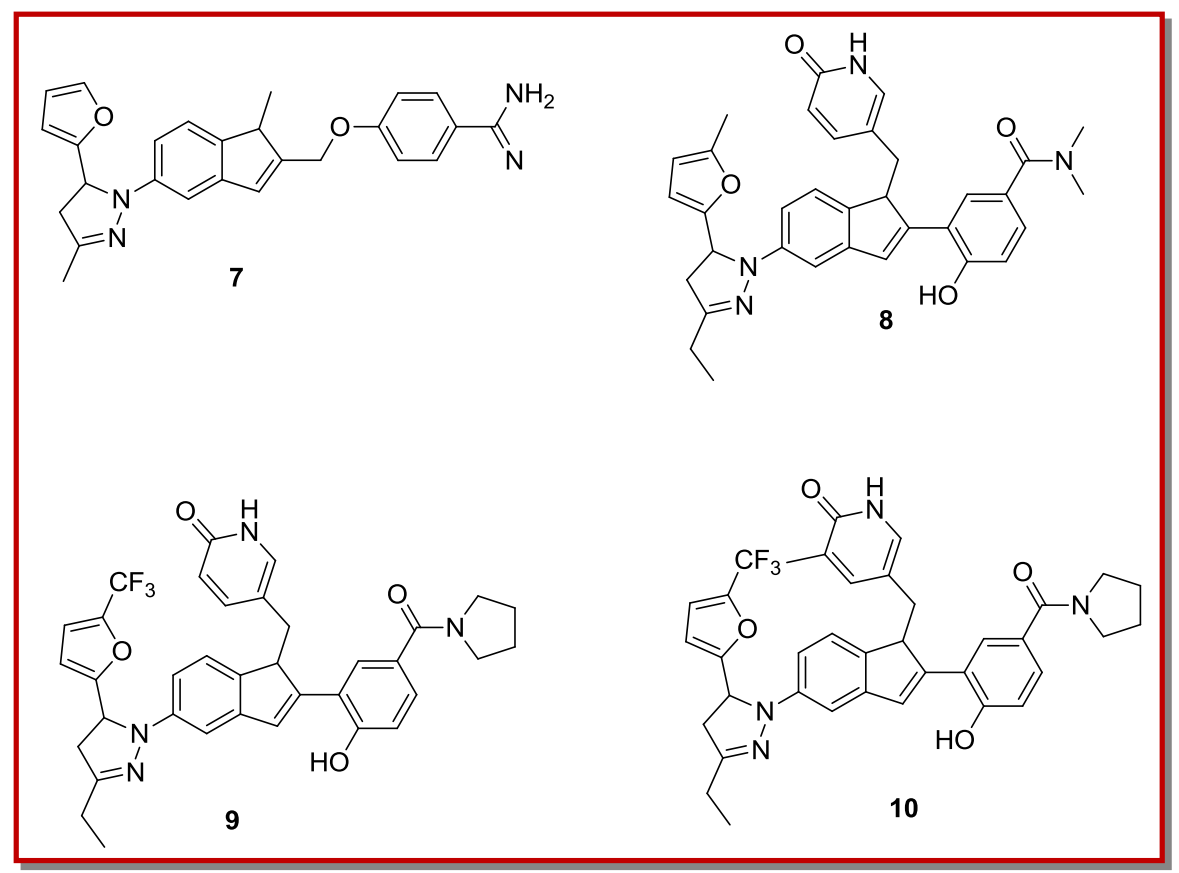

similar to the caparavarine structure showed maximum activity against the virus (Loksha et al., 2005). Computational studies also confirm the imidazole moiety as a potential candidate for the treatment of HIV -AIDS. In this regard, a study was done using Levenberg-Marquardt Algorithm trained Neural Network (ANN) for the QSAR of 5-pheny-1-phenyl-amino-1Himidazole compounds. Imidazole is the potential candidate for the treatment of AIDs (Chamjangali et al., 2007). As imidazole and its derivatives show significant activity, so there is a need to explore more in this field to introduce a drug for the treatment of HIV-AIDS.

\section{Anti-cancer}

Cancer is a disease which accompanied by the mortality causes due to the malfunctioning of the cells. The need of time is to develop some new drugs which can bind to the proteins of the infected cells and help to destroy their regeneration. Synthetic chemists are trying to produce some new drugs to treat the cancer patients. Nitrogenous compounds are found to be very good anti -cancerous agents. In this regard a natural product with the imidazole moiety(-)-dibromophakellstatin (11) isolated from the marine sponges, was tested against 36 different cancerous cell line. The more resistance was observed for the ovarian OVXF 899L (Zöllinger et al., 2007).

Some derivatives of the acetylhydrazole containing 2(phenylthiomethyl)-1H-benzo-[d]-imidazole were synthesized and tested against five cancerous cell lines including PC-9, A549, A375, HCT116, and HepG2. Activity was determined by using MTT analysis. It was found that among them the two compounds $\mathrm{N}-(5-$ bromo-2-hydroxybenzylidene)-2-(2-(phenylthiomethyl)

-1H-benzo[d]-imidazol-1-yl)acetohydrazide (12) and N(2,4-dihydroxybenzylidene)-2-(2-(phenylthiomethyl)1H-benzo[d]-imidazol-1-yl)acetohydrazide (13) showed excellent activities against all the five cancer cell lines (Liu et al., 2012). Özkay et al, synthesized some derivatives of imidazole i.e imidazole-(benz)azole and imidazole piperazine and tested them against the breast (MCF-7) carcinoma and colon (HT-29) cancerous cell line. Compounds with the triazole moiety showed maximum cytotoxic activity against the colon cancer cell lines (Özkay et al., 2010). Tert-butyl-2(4,5-dihydrogen-4,4,5,5-tetramethyl-3-O-1H-imidazole-3-cationic-1oxyl-2)-pyrrolidine-1-carboxylic ester (L-NNP) (14) is a stable nitroxyl nitroxide radical possess a activity against the human breast cancer MCF-7 and MDA-MB231 cell lines. When this compound was tested against the isogenic human hepatoma HepG2 cell lines it showed activity and found as a potent inhibitor for the lung cancer cell line (Guo et al., 2012).

Sulfa drugs are famous for the broad spectrum of activities. Amidosulfonamidomethane linked bis-imidazoles (15) were synthesized and found potent against the colon, prostate and lungs cancer cell lines (Premakumari et al., 2014). Anthra[1,2-d]imidazole-6,11 -dione derivatives were synthesized and tested for their cytotoxic activities. Maximum derivatives were found active against different cancerous cell lines (Chen et al., 2013a). Some derivatives of 2-[(4,5-dimethyl-1-(arylamino)-1H-imidazol-2-yl)thio]-1-(aryl)ethanone were synthesized and evaluated them for anti-cancerous activities by brine shrimp lethality assay and found active (Yurttaş et al., 2013). Copper complex of imidazole with taurine Schiff base was synthesized and tested for its cytotoxic analysis. Due to specific $S$ shape molecule, it was found that the copper complex of 
imidazole showed maximum inhibition against the human tumor cell lines in vitro ( $\mathrm{Li}$ et al., 2014). The hybrid between imidazole and 2-phenylbenzofuran (16) was synthesized and evaluated against the cancerous cell lines. It was proposed that the molecules in which imidazolyl-3-position is substituted with a naphthylacyl or bromophenacyl group show maximum inhibition against the liver carcinoma (SMMC-7721) cell-lines (Yang et al., 2012). A series of 4-aryl-5-(3,4,5-trimethoxy -phenyl)-2-alkylthio-1H-imidazoles were synthesized and in vitro tested against the four cancerous cell lines including HT-29, MCF-7, NIH-3T3, AGS. It was found that the compound with the 3,4,5-trimethoxy substitution is more active against the all four cell lines (Assadieskandar et al., 2013). Derivatives of 2-(phenyl)$3 \mathrm{H}$-benzo[d]imidazole-5-carboxylic acids were synthesized and in vitro studied against the three breast cancer cell lines MDA-MB231, MDA-MB468, and MCF7. Compound with the 5-fluoro-2-hydroxyphenyl (17) substituent was found to be the most active derivative of the series with GI50 values of 6.2, 4.1 and $0.2 \mathrm{LM}$ against MDAMB468, MDA-MB231, and MCF7 breast cancer cell lines, respectively (Karthikeyan et al. 2013). Some amino substituted xantheno[1,2-d]imidazole derivatives were synthesized and tested against the breast cancer cell lines (Kostakis et al., 2008). The compound with substituted at the 2 and 5 position of the imidazole showed maximum inhibition and it was found that with the increase of the $\mathrm{N}$-alkyl basity increase in activity was observed metal complex of chlorido-[1,3-dimethyl-4,5-diarylimidazol-2-ylidene] were synthesized and tested for their cytotoxic activity against four human cancer cell lines and found active candidate for the treatment of cancer (Kaps et al., 2012). A series of N-heterocycle carbine silver complexes with 4,5-di(p-isopropylphenyl)-1H-imidazole and 4,5-di(pchlorophenyl)-1H-imidazole show activity against the human breast cancer cell lines (Streciwilk et al., 2014). Imidazole polyamide conjugates linked with pyrrolo $[2,1][1,4]$ benzodiazepine (PBD) dimers were synthesized by the Lown group possess the potent anti-cancer activities against many cancer cell lines (Kumar and Lown, 2005). From the literature, it is found that in near future imidazole substituted group can be used for the introduction of new drugs for the treatment of cancer especially for the treatment of breast cancer.

\section{Antitubercular}

Xiaoyun Lu et al. tested the 4-(2,6-dichlorobenzyloxy) phenylimidazoles and their derivatives against the Mycobacterium tuberculosis H37Rv using the microplate alamar blue assay (MABA) for anti tuberculosis activities compounds were found to possess good activities (Lu et al., 2012). Moura et al (2012) synthesized the naphthoimidazoles (18-21) starting from the beta-lapachone. These compounds were tested for TB analysis against the $M$. tuberculosis H37Rv (pansusceptible), rifampicin-resistant (RIFr, ATCC 35338) and isoniazid-resistant (INHr, ATCC 35822) strains of bacteria among them the compounds with imidazole units showed good to moderate activity against these strains (Moura et al., 2012).

A series of N-(4-(4-chloro-1H-imidazol-1-yl)-3-methoxyphenyl)amide (22) and N-(4-(4-chloro-1H-imidazol-1yl)-3-methoxyphenyl) sulfonamide (23) derivatives showed potent antitubercular activities activity against M. tuberculosis H37Rv, M. smegmatis, M. fortuitum and MDR-TB strains (Ranjith et al., 2014). Jadhav et al (2009) has synthesized a series of 2-[4-(1H-[1,2,4]-triazol-1-yl) phenyl]-1-substituted-4,6-difluoro-1H-benzo[d] imidazole derivatives by the alkylation of 2-[4- $(1 \mathrm{H}-$ [1,2,4]-triazol-1-yl)phenyl]-4,6-difluoro-1H-benzo[d] imidazole with substituted alkyl and aryl halides. They preliminary tested their compounds against different strains of bacteria including Escherichia coli, Salmonella typhosaand, Staphylococcus aureus and Pseudomonas aeruginosa, and after then screened compounds were tested for their antitubercular activity against $M$. tuberculosis $\mathrm{H} 37 \mathrm{Rv}$ strain by broth microdilution assay method. After the antibacterial evaluation, it was found that the compounds having electronegative substituents possess promising antimicrobials. It was also observed<smiles>O=C1N[C@H]2n3c(cc(Br)c3Br)C(=O)N3CCC[C@]23N1</smiles>

11<smiles>O=C(N/N=C/c1cc(Br)ccc1O)n1c(CSc2ccccc2)nc2ccccc21</smiles>

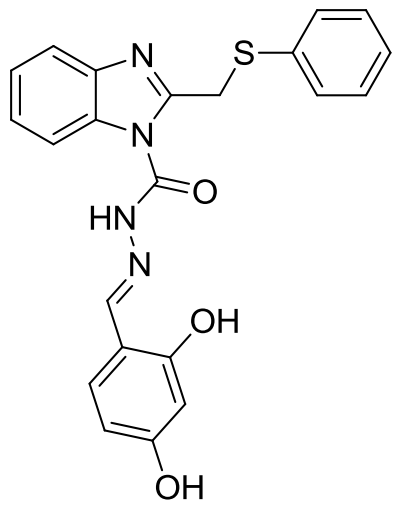

13 


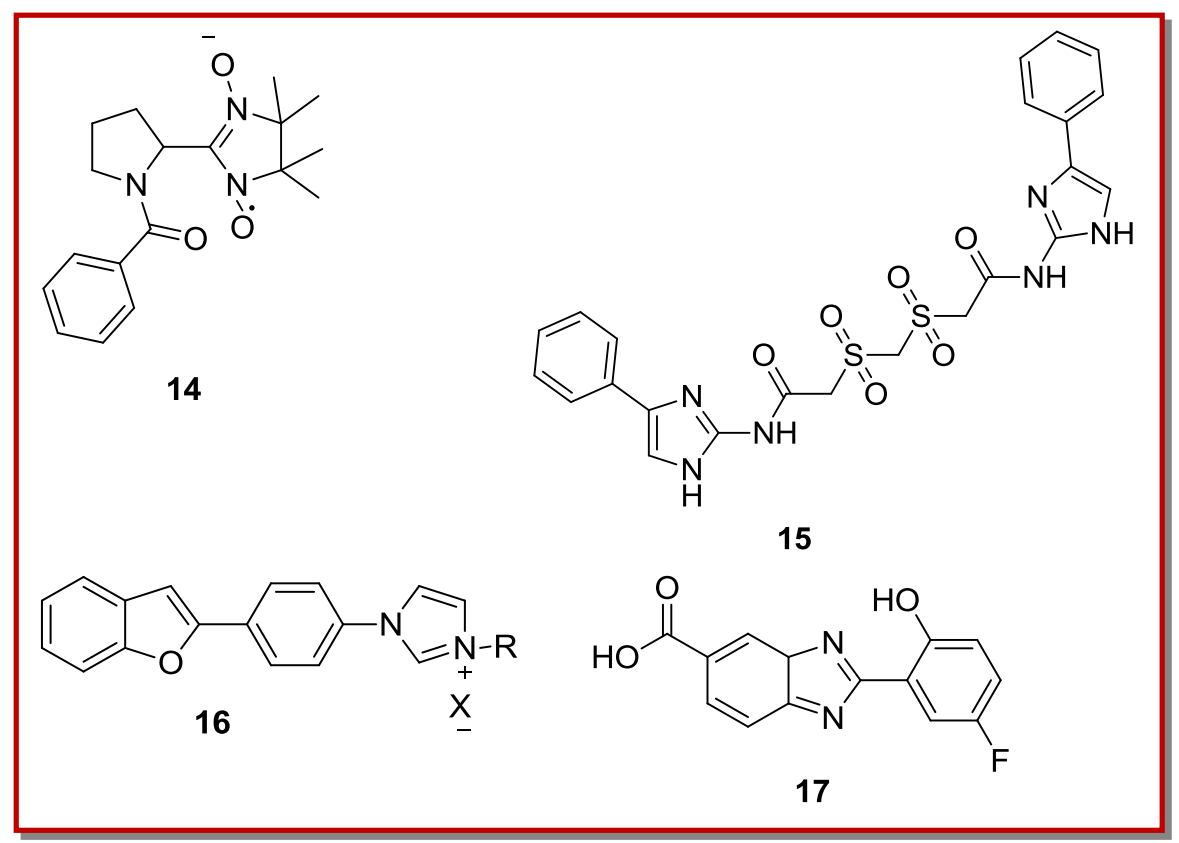

that the compounds with good antimicrobials activities can possess better antimycobacterials activity as well (Jadhav et al., 2009). Marrapu et al. synthesized some chalcone substituted imidazole and found active against the virulent M. tuberculosis (Marrapu et al., 2011). Some tetrazolo[1,5-a]quinoline based tetrasubstituted imidazole derivatives were synthesized and tested for their anti-TB analysis approximately all the compounds were active against the bacteria (Mungra et al., 2012).

Some pyridine substituted imidazoles were synthesized but unfortunately, these compounds could not show good activity against the different strain of bacteria (Sirisha et al., 2011). A series of 51 benzimidazoles starting from the 4-floro-3-nitrobenzoic acid (24) were synthesized (Yoon et al., 2015). Among these 51 imidazoles, the ethyl 2-(4-(trifluoromethyl)phenyl)-1-(2morpholinoethyl)-1H-benzo[d]imidazole-5-carboxylate found most active on $\mathrm{IC}_{50}$ member against the $M$. tuberculosis H37Rv strain of bacteria. From the observation, it was found the lead compound could be used for the future analysis to introduce a new TB drug in the market (Yoon et al., 2015). Thiadiazole and imidazoles show a broad spectrum of bioactivities (Bhongade et al. 2013). Imidazo(2,1-b)-1,3,4-thiadiazole were synthesized and tested against in vitro antitubercular activity against $M$. tuberculosis H37Rv strain of bacteria (Patel et al., 2013). Among them the compound 2-(1-methyl-1H-imidazol-2-yl)-6-(4-nitro-phenyl) imidazo[2,1-b][1,3,4]thiadiazole showed maxi-mum inhibition. Filament temperature sensitive protein $\mathrm{Z}$ (FtsZ) are very famous protein and used as a target for the treatment of TB. A series of 2,5,6-trisubstituted imidazoles (25) were synthesized and tested against the Fts $\mathrm{Z}$ protein and most of the derivatives show MIC values of $0.63-12.5 \mathrm{Lg} / \mathrm{mL}$ range (Park et al., 2014). N'- substituted-2-(5-nitrofuran or 5-nitrothiophen-2-yl)-3Hbenzo[d]imida-zole-5-carbohydrazide derivatives shows maximum inhibition activity against the mycobacterial cell (Camacho et al., 2011). As bacteria are becoming resistant to the available drugs and there is a need to introduce more drugs so literature shows that imidazole scaffold can help to lessen this problem.

\section{Anti-hepatitis C}

An important trauma of the world is facing today is to establish drugs against hepatitis $\mathrm{C}$ virus (HCV). More than 170 million people across the world are affected by this fatal disease. The standard treatment of this disease is a combination of ribavirin with pegylated interferonalpha. Unfortunately, these medicines show activity only against type 2 and 3 and found to be inactive against 1 and 4 genotypes of HCV virus. Due to this lack of activity, some severe side effects are also being spread. In order to cope and stop this adverse effect, there is a need for the development of new drugs (Gamble et al., 2009). The computational study showed that imidazole compounds have a tendency to play a significant role in the introduction of new drugs for the treatment of antiviral drugs especially for hepatitis C (Srivastava and Shukla, 2013). Imidazole derivatives of L-ascorbic acid and imino-ascorbic acid possess strong activity against the hepatitis $\mathrm{C}$ virus $(\mathrm{HCV})$ replication (Wittine et al., 2012). Ujjinamatad et al. synthesized the imidazole derivative (26) and in vitro evaluated against four different viruses from Flaviviridae family, hepatitis $C$ virus (HCV), West Nile virus (WNV), dengue virus (DENV), and the Japanese encephalitis virus (JEV), employing both an RNA and a DNA substrate. The compound showed maximum activity against WNV and $\mathrm{HCV}$ with an $\mathrm{IC}_{50}$ of 23 and $37 \mathrm{MM}$, in the presence of DNA substrate (Ujjinamatada et al., 2007). 
<smiles>CC1(C)CCc2c(c3ccccc3c3nc(-c4ccccn4)[nH]c23)O1</smiles>

18<smiles>CC1(C)CCc2c(c3[nH]c(-c4cccnc4)nc3c3ccccc23)O1</smiles><smiles>CC1(C)CCc2c(c3[nH]c(-c4cncc5ccccc45)nc3c3ccccc23)O1</smiles><smiles>CC1(C)CCc2c(c3[nH]c(-c4nccc5ccccc45)nc3c3ccccc23)O1</smiles>

20
In addition to promising antibacterial activities, sulfa drugs are also playing their significant role in the development of new drugs to cure hepatitis C. NPhenylbenzene sulfonamides are consider as hepatitis $\mathrm{C}$ polymerase inhibitors (May et al., 2012). Hepatitis B is the world's 9th infection which is the cause of death. Sulfa drug with imidazole moiety 1-isopropylsulfonyl-2 -amine benzimidazole derivatives shows potent inhibitory activity against hepatitis B (Li et al., 2007). Benzimidazole substituted with coumarin a natural product derivatives 1-[(2,3,4,6-tetra-O-acetyl)glucopy-ranos-1yl]-2-[(6-bromocoumarin-3-yl)methylenethio] benzimidazol (27) and 2-[(6-bromocoumarin-3-yl)methy -lenethio]-5-fluorobenzimidazole show potent activity against the HCV (Hwu et al., 2008). 2-Iminobenzimidazole (IBI) is a well-known hepatitis C enzyme inhibitor. Some analogs of IBI with characteristic imidazole group were synthesized by Windisch et al. when tested against the hepatitis virus they showed maximum inhibition (Windisch et al., 2014). With the advancement in imidazole chemistry, there is a need to introduce new imidazole substituted compounds and tested them for the treatment of hepatitis C.

\section{Conclusion}

Imidazole and their derivatives are important scaffolds used in the treatment of many diseases like HIV-AIDS, cancer, tuberculosis and hepatitis C. Many derivatives possess the strong activities and some other are with moderate activity. They have a potential to be used as potential drugs in future.

\section{Acknowledgement}

A. M. greatly acknowledge the higher education commission of Pakistan and COMSATS IIT.

\section{References}

Anderson EB, Long TE. Imidazole- and imidazoliumcontaining polymers for biology and material science applications. Polymer 2010; 51: 2447-54.

Assadieskandar A, Amini M, Ostad SN, Riazi GH, Cheraghi-

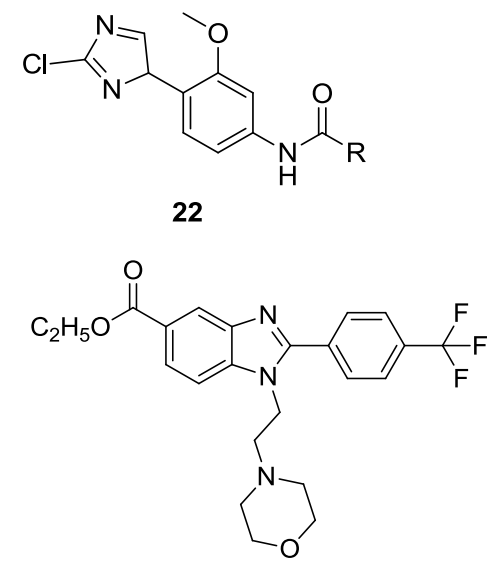

24<smiles>[R]P(=O)(O)Nc1ccc(C2C=NC(Cl)=N2)c(OC)c1</smiles>

23<smiles>NC(=O)c1ncn(C2OC(CO)C(O)C2O)c1C1N=C(N)NC(N)=N1</smiles>

26

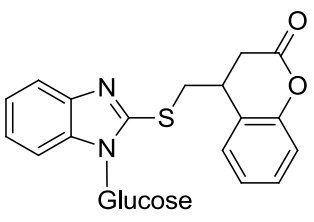

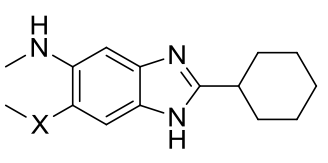

25 
Shavi T, Shafiei B, Shafiee A. Design, synthesis, cytotoxic evaluation and tubulin inhibitory activity of 4 -aryl-5-(3,4,5trimethoxyphenyl)-2-alkylthio-1H-imidazole derivatives. Bioorgan Med Chem. 2013; 21: 2703-09.

Banothu J, Gali R, Velpula R, Bavantula R. Brønsted acidic ionic liquid catalyzed an efficient and eco-friendly protocol for the synthesis of 2, 4, 5-trisubstituted-1H-imidazoles under solvent-free conditions. Arabian J Chem. 2013.

Basu A, Jasu K, Jayaprakash V, Mishra N, Ojha P, Bhattacharya S. Development of CoMFA and CoMSIA models of cytotoxicity data of anti-HIV-1-phenylamino-1H-imidazole derivatives. Eur J Med Chem. 2009; 44: 2400-07.

Bellina F, Cauteruccio S, Rossi R. Synthesis and biological activity of vicinal diaryl-substituted $1 \mathrm{H}$-imidazoles. Tetrahedron 2007; 63: 4571-24.

Bhongade BA, Talath S, Gadad RA, Gadad AK. Biological activities of imidazo[2,1-b][1,3,4] thiadiazole derivatives: A review. J Saudi Chem Soc. 2013.

Camacho J, Barazarte A, Gamboa N, Rodrigues J, Rojas R, Vaisberg A, Gilman R, Charris J. Synthesis and biological evaluation of benzimidazole-5-carbohydrazide derivatives as antimalarial, cytotoxic and antitubercular agents. Bioorgan Med Chem. 2011; 19: 2023-29.

Chamjangali M, Beglari M, Bagherian G. Prediction of cytotoxicity data (CC50) of anti-HIV 5-pheny-l-phenylamino $-1 \mathrm{H}$-imidazole derivatives by artificial neural network trained with Levenberg-Marquardt algorithm. J Mol Graph Model. 2007; 26:360-67.

Chen CL, Chang DM, Chen TC, Lee CC, Hsieh HH, Huang FC, Huang KF, Guh JH, Lin JJ, Huang HS. Structure-based design, synthesis and evaluation of novel anthra[1,2-d] imidazole-6,11-dione derivatives as telomerase inhibitors and potential for cancer polypharmacology. Eur J Med Chem. 2013a; 60: 29-41.

Chen TC, Yu DS, Huang KF, Fu YC, Lee CC, Chen CL, Huang FC, Hsieh HH, Lin JJ, Huang HS. Structure-based design, synthesis and biological evaluation of novel anthra[1,2-d] imidazole-6,11-dione homologues as potential antitumor agents. Eur J Med Chem. 2013b; 69: 278-93.

Chen X, Jia C, Wan Z, Yao X. Organic dyes with imidazole derivatives as auxiliary donors for dye-sensitized solar cells: Experimental and theoretical investigation. Dyes Pigments. 2014; 104: 48-56.

De Walque D. HIV/AIDS: Transmission, treatment, and prevention, Economics. In: Encyclopedia of health economics. Culyer AJ (ed). San Diego, Elsevier, 2014, pp 468-76.

Dostert P, Melloni P, Della Torre A, Varasi M, Merlini L, Bonsignori A, Ricciardi S. Research of potential antidepressant drugs with $\mathrm{a}_{2}$-adrenoreceptor antagonist and NA -uptake inhibiting properties: Synthesis of 2-(1-hydroxy-2phenoxy-2-phenyl)ethyl-4,5-dihydro-1H-imidazole derivatives. Eur J Med Chem. 1990, 25: 757-63.

Fraser M, Berlin A, Ouellet V, Saad F, Bristow RG. Prostate cancer genomics as a driver of personalized medicine. In: Cancer genomics. Dellaire G, Berman JN, Arceci RJ (eds). Boston, Academic Press, 2014, pp 233-45.

Gamble C, Trotard M, Seyec JL, Abreu-Guerniou V, Gernigon
N, Berrée F, Carboni B, Felden B, Gillet R. Antiviral effect of ribonuclease conjugated oligodeoxynucleotides targeting the IRES RNA of the hepatitis C virus. Bioorg Med Chem Lett. 2009; 19: 3581-85.

Gong Y, Somersan Karakaya S, Guo X, Zheng P, Gold B, Ma Y, Little D, Roberts J, Warrier T, Jiang X, et al. Benzimidazolebased compounds kill Mycobacterium tuberculosis. Eur J Med Chem. 2014; 75: 336-53.

Guo J, Zhang Y, Zhang J, Liang J, Zeng L, Guo G. Anti-cancer effect of tert-butyl-2(4,5-dihydrogen-4,4,5,5-tetramethyl-3-O1H-imidazole-3-cationic-1-oxyl-2)-pyrrolidine-1-carboxylic ester on human hepatoma HepG2 cell line. Chem Biol Interact. 2012; 199: 38-48.

Hwu JR, Singha R, Hong SC, Chang YH, Das AR, Vliegen I, De Clercq E, Neyts J. Synthesis of new benzimidazole-coumarin conjugates as anti-hepatitis C virus agents. Antivir Res. 2008; 77: $157-62$.

Jadhav GR, Shaikh MU, Kale RP, Shiradkar MR, Gill CH. SAR study of clubbed $[1,2,4]$-triazolyl with fluorobenzimidazoles as antimicrobial and antituberculosis agents. Eur J Med Chem. 2009; 44: 2930-35.

Kannan V, Sreekumar K. Clay supported titanium catalyst for the solvent free synthesis of tetrasubstituted imidazoles and benzimidazoles. J Mol Catal A Chem. 2013; 376: 34-39.

Kaps L, Biersack B, Müller-Bunz H, Mahal K, Münzner J, Tacke M, Mueller T, Schobert R. Gold(I)-NHC complexes of antitumoral diarylimidazoles: Structures, cellular uptake routes and anti-cancer activities. J Inorg Biochem. 2012; 106: $52-58$.

Karthikeyan C, Solomon VR, Lee H, Trivedi P. Synthesis and biological evaluation of 2-(phenyl)-3H-benzo[d]imidazole-5carboxylic acids and its methyl esters as potent anti-breast cancer agents. Arabian J Chem. 2013.

Kostakis IK, Pouli N, Marakos P, Kousidou OC, Roussidis A, Tzanakakis GN, Karamanos NK. Design, synthesis and cell growth inhibitory activity of a series of novel aminosubstituted xantheno[1,2-d]imidazoles in breast cancer cells. Bioorgan Med Chem. 2008; 16: 3445-55.

Kumar R, Lown JW. Design, synthesis and in vitro cytotoxic studies of novel bis-pyrrolo[2,1][1,4] benzodiazepine-pyrrole and imidazole polyamide conjugates. Eur J Med Chem. 2005; 40: $641-54$

Li M, kong LL, Gou Y, Yang F, Liang H. DNA binding, cytotoxicity and apoptosis induction activity of a mixedligand copper(II) complex with taurine Schiff base and imidazole. Spectrochim Acta A. 2014; 128: 686-93.

Li Y-F, Wang G-F, Luo Y, Huang W-G, Tang W, Feng C-L, Shi L-P, Ren Y-D, Zuo J-P, Lu W. Identification of 1-isopropylsulfonyl-2-amine benzimidazoles as a new class of inhibitors of hepatitis B virus. Eur J Med Chem. 2007; 42: 1358-64.

Linas BP, Hu H, Barter DM, Horberg M. Hepatitis C screening trends in a large integrated health system. Am J Med. 2014; 127: 398-405.

Liu T, Sun C, Xing X, Jing L, Tan R, Luo Y, Huang W, Song H, Li Z, Zhao Y. Synthesis and evaluation of 2-[2-(phenylthiomethyl)-1H-benzo[d] imidazol-1-yl)acetohydrazide derivatives as antitumor agents. Bioorg Med Chem Lett. 


\section{2; 22: 3122-25}

Loksha YM, El-Barbary AA, El-Badawi MA, Nielsen C, Pedersen EB. Synthesis of 2-(aminocarbonylmethylthio)-1Himidazoles as novel capravirine analogues. Bioorgan Med Chem. 2005; 13: 4209-20.

Lu X, Liu X, Wan B, Franzblau SG, Chen L, Zhou C, You Q. Synthesis and evaluation of anti-tubercular and antibacterial activities of new 4-(2,6-dichlorobenzyloxy)phenyl thiazole, oxazole and imidazole derivatives. Eur J Med Chem. 2012; 49: 164-71.

Marrapu VK, Chaturvedi V, Singh S, Singh S, Sinha S, Bhandari K. Novel aryloxy azolyl chalcones with potent activity against Mycobacterium tuberculosis H37Rv. Eur J Med Chem. 2011; 46: 4302-10.

May MM, Brohm D, Harrenga A, Marquardt T, Riedl B, Kreuter J, Zimmermann H, Ruebsamen-Schaeff $\mathrm{H}$, Urban A. Discovery of substituted N-phenylbenzenesulphonamides as a novel class of non-nucleoside hepatitis $C$ virus polymerase inhibitors. Antivir Res. 2012; 95: 182-91.

Mirjalili BF, Bamoniri AH, Zamani L. One-pot synthesis of 1,2, 4,5-tetrasubstituted imidazoles promoted by nano. Sci Iranica. 2012; 19: 565-68.

Moura KCG, Carneiro PF, Pinto MdCFR, da Silva JA, Malta VRS, de Simone CA, Dias GG, Jardim GAM, Cantos J, Coelho TS, et al. 1,3-Azoles from ortho-naphthoquinones: Synthesis of aryl substituted imidazoles and oxazoles and their potent activity against mycobacterium tuberculosis. Bioorgan Med Chem. 2012; 20: 6482-88.

Mungra DC, Kathrotiya HG, Ladani NK, Patel MP, Patel RG. Molecular iodine catalyzed synthesis of tetrazolo[1,5-a]quinoline based imidazoles as a new class of antimicrobial and antituberculosis agents. Chinese Chem Lett. 2012; 23: 1367-70.

Nagarajan N, Prakash A, Velmurugan G, Shakti N, Katiyar M, Venuvanalingam P, Renganathan R. Synthesis, characterisation and electroluminescence behaviour of $\Pi$-conjugated imidazole-isoquinoline derivatives. Dyes Pigments. 2014a; 102: $180-88$.

Nagarajan N, Vanitha G, Ananth DA, Rameshkumar A, Sivasudha T, Renganathan R. Bioimaging, antibacterial and antifungal properties of imidazole-pyridine fluorophores: Synthesis, characterization and solvatochromism. J Photoch Photobio B. 2013; 127: 212-22.

Nagarajan N, Velmurugan G, Prabhu G, Venuvanalingam P, Renganathan R. A combined experimental and theoretical investigation of imidazole-carbazole fluorophores. J Lumin. 2014b; 147: 111-20.

Özkay Y, Işıkdağ İ, İncesu Z, Akalın G. Synthesis of 2substituted-N-[4-(1-methyl-4,5-diphenyl-1H-imidazole-2-yl) phenyl]acetamide derivatives and evaluation of their anticancer activity. Eur J Med Chem. 2010; 45: 3320-28.

Park B, Awasthi D, Chowdhury SR, Melief EH, Kumar K, Knudson SE, Slayden RA, Ojima I. Design, synthesis and evaluation of novel 2,5,6-trisubstituted benzimidazoles targeting FtsZ as antitubercular agents. Bioorgan Med Chem. 2014; 22: 2602-12.

Patel HM, Noolvi MN, Sethi NS, Gadad AK, Cameotra SS.
Synthesis and antitubercular evaluation of imidazo[2,1-b] $[1,3,4]$ thiadiazole derivatives. Arabian J Chem. 2013.

Premakumari C, Muralikrishna A, Padmaja A, Padmavathi V, Park SJ, Kim TJ, Reddy GD. Synthesis, antimicrobial and anti -cancer activities of amido sulfonamido methane linked bis heterocycles. Arabian J Chem. 2014; 7: 385-95.

Ranjith PK, Pakkath R, Haridas KR, Kumari SN. Synthesis and characterization of new N-(4-(4-chloro-1H-imidazol-1-yl)-3methoxyphenyl)amide/sulfonamide derivatives as possible antimicrobial and antitubercular agents. Eur J Med Chem. 2014; 71: 354-65.

Roy K, Leonard JT. QSAR by LFER model of cytotoxicity data of anti-HIV 5-phenyl-1-phenylamino- $1 \mathrm{H}$-imidazole derivatives using principal component factor analysis and genetic function approximation. Bioorgan Med Chem. 2005; 13: 2967 -73 .

Safari J, Gandomi-Ravandi S, Akbari Z. Sonochemical synthesis of 1,2,4,5-tetrasubstituted imidazoles using nanocrystalline $\mathrm{MgAl}_{2} \mathrm{O}_{4}$ as an effective catalyst. J Adv Res. 2013; 4: 509-14.

Saffari Jourshari M, Mamaghani M, Shirini F, Tabatabaeian K, Rassa M, Langari H. An expedient one-pot synthesis of highly substituted imidazoles using supported ionic liquidlike phase (SILLP) as a green and efficient catalyst and evaluation of their antimicrobial activity. Chinese Chem Lett. 2013; 24: 993-96.

Serrao E, Xu Z-L, Debnath B, Christ F, Debyser Z, Long Y-Q, Neamati N. Discovery of a novel 5-carbonyl-1H-imidazole-4carboxamide class of inhibitors of the HIV-1 integraseLEDGF/p75 interaction. Bioorgan Med Chem. 2013; 21: 5963 -72 .

Sharma D, Narasimhan B, Kumar P, Judge V, Narang R, De Clercq E, Balzarini J. Synthesis, antimicrobial and antiviral evaluation of substituted imidazole derivatives. Eur J Med Chem. 2009; 44: 2347-53.

Sirisha K, Bikshapathi D, Achaiah G, Reddy VM. Synthesis, antibacterial and antimycobacterial activities of some new 4aryl/heteroaryl-2,6-dimethyl-3,5-bis-N-(aryl)-carbamoyl-1,4dihydropyridines. Eur J Med Chem. 2011; 46: 1564-71.

Sorrenti V, Salerno L, Di Giacomo C, Acquaviva R, Siracusa MA, Vanella A. Imidazole derivatives as anti-oxidants and selective inhibitors of nNOS. Nitric Oxide. 2006; 14: 45-50.

Srivastava AK, Shukla N. Quantitative structure activity relationship (QSAR) studies on a series of imidazole derivatives as novel ORL1 receptor antagonists. J Saudi Chem Soc. 2013, 17: 321-28.

Streciwilk W, Cassidy J, Hackenberg F, Müller-Bunz H, Paradisi F, Tacke M. Synthesis, cytotoxic and antibacterial studies of p-benzyl-substituted NHC-silver(I) acetate compounds derived from 4,5-di-p-diisopropylphenyl- or 4,5di-p-chlorophenyl-1H-imidazole. J Organomet Chem. 2014; 749: 88-99.

Tremblay M, Bonneau P, Bousquet Y, DeRoy P, Duan J, Duplessis M, Gagnon A, Garneau M, Goudreau N, Guse I, et al. Inhibition of HIV-1 capsid assembly: Optimization of the antiviral potency by site selective modifications at N1, C2 and C16 of a 5-(5-furan-2-yl-pyrazol-1-yl)-1H-benzimidazole 
scaffold. Bioorg Med Chem Lett. 2012; 22: 7512-17.

Uçucu Ü, Karaburun NG, Işikdağ İ. Synthesis and analgesic activity of some 1-benzyl-2-substituted-4,5-diphenyl-1Himidazole derivatives. Il Farmaco 2001; 56: 285-90.

Ujjinamatada RK, Baier A, Borowski P, Hosmane RS. An analogue of AICAR with dual inhibitory activity against WNV and HCV NTPase/helicase: Synthesis and in vitro screening of 4-carbamoyl-5-(4,6-diamino-2,5-dihydro-1,3,5triazin-2-yl)imidazole-1- $\beta$-d-ribofuranoside. Bioorg Med Chem Lett. 2007; 17: 2285-88.

Windisch MP, Jo S, Kim H-Y, Kim S-H, Kim K, Kong S, Jeong H, Ahn S, No Z, Hwang JY. Discovery of 2-iminobenzimidazoles as potent hepatitis $C$ virus inhibitors with a novel mechanism of action. Eur J Med Chem. 2014; 78: 35-42.

Wittine K, Stipković Babić M, Makuc D, Plavec J, Kraljević Pavelić S, Sedić M, Pavelić K, Leyssen P, Neyts J, Balzarini J, Mintas M. Novel 1,2,4-triazole and imidazole derivatives of 1 -ascorbic and imino-ascorbic acid: Synthesis, anti-HCV and antitumor activity evaluations. Bioorgan Med Chem. 2012; 20: 3675-85.

Xue W-J, Li H-Z, Gao F-F, Wu A. Synthesis of trisubstituted imidazoles via a convergent reaction network from methyl ketones and benzoins. Tetrahedron 2014; 70: 239-44.

Yang XD, Wan WC, Deng XY, Li Y, Yang LJ, Li L, Zhang HB. Design, synthesis and cytotoxic activities of novel hybrid compounds between 2-phenylbenzofuran and imidazole. Bioorg Med Chem Lett. 2012; 22: 2726-29.

Yoon YK, Ali MA, Wei AC, Choon TS, Ismail R. Synthesis and evaluation of antimycobacterial activity of new benzimidazole aminoesters. Eur J Med Chem. 2015; 93: 614-24.

Yurttaş L, Duran M, Demirayak Ş, Gençer HK, Tunalı Y. Synthesis and initial biological evaluation of substituted 1phenylamino-2-thio-4,5-dimethyl-1H-imidazole derivatives. Bioorg Med Chem Lett. 2013; 23: 6764-68.

Zhan P, Liu X, Zhu J, Fang Z, Li Z, Pannecouque C, Clercq ED. Synthesis and biological evaluation of imidazole thioacetanilides as novel non-nucleoside HIV-1 reverse transcriptase inhibitors. Bioorgan Med Chem. 2009; 17: 5775-81.

Ziarani GM, Badiei A, Lashgari N, Farahani Z. Efficient onepot synthesis of 2,4,5-trisubstituted and 1,2,4,5-tetra-substituted imidazoles using SBA-Pr-SO3H as a green nano catalyst. J Saudi Chem Soc. 2013.

Ziarani GM, Dashtianeh Z, Nahad MS, Badiei A. One-pot synthesis of 1,2,4,5-tetra substituted imidazoles using sulfonic acid functionalized silica ( $\mathrm{SiO} 2-\mathrm{Pr}-\mathrm{SO} 3 \mathrm{H})$. Arabian J Chem. 2013.

Ziółkowska NE, Michejda CJ, Bujacz GD. Structure of HIV-1 nonnucleoside reverse transcriptase inhibitors derivatives of N-benzyl-benzimidazole with different substituents in position 4. J Mol Struct. 2010; 963: 188-93.

Zöllinger M, Kelter G, Fiebig H-H, Lindel T. Antitumor activity of the marine natural product dibromophakellstatin in vitro. Bioorg Med Chem Lett. 2007; 17: 346-49.

Zoraghi R, Reiner NE. Protein interaction networks as starting points to identify novel antimicrobial drug targets. Curr Opin Microbiol. 2013; 16: 566-72.

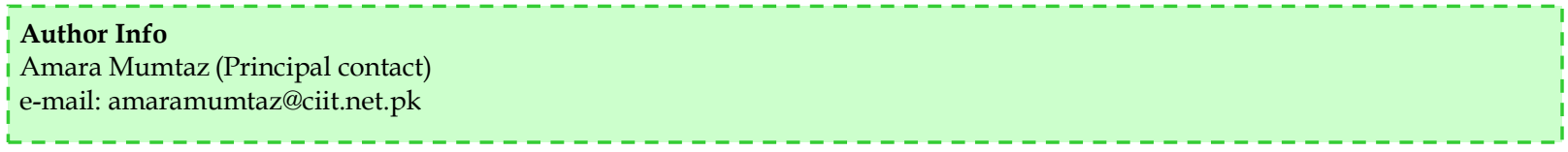




\section{Your feedback about this paper}

1. Number of times you have read this paper 0

2. Quality of paper Click

3. Your comments

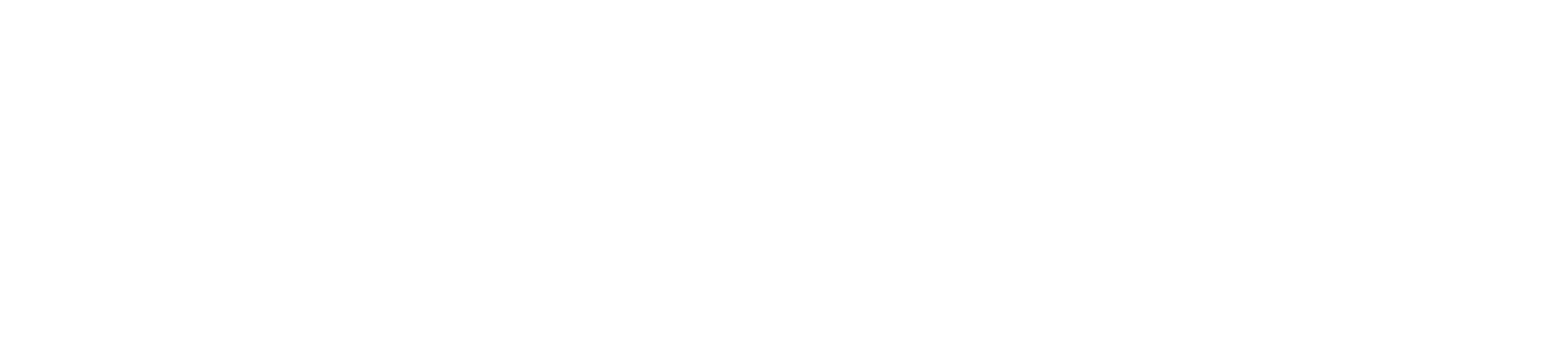

